\title{
Design of Anchorage in Reinforced Concrete Members
}

\author{
By Hamdi Kaan Kok \\ An MENG Project presented to Ryerson University \\ In fulfillment of the requirements for the degree of \\ Masters of Engineering in the program Civil Engineering
}

$12 / 20 / 2019$

Toronto, Ontario Canada

Hamdi Kaan Kok. 2019 


\section{Table of Contents}

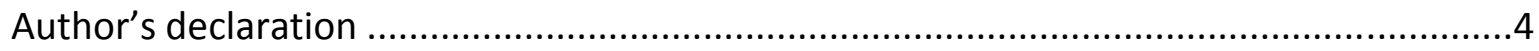

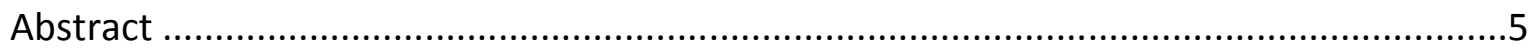

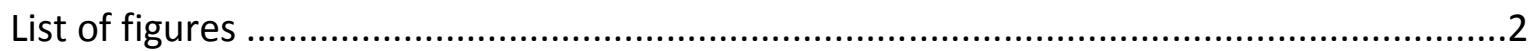

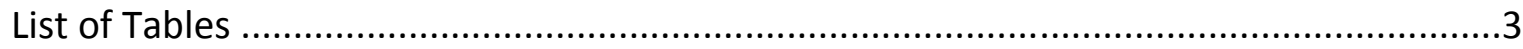

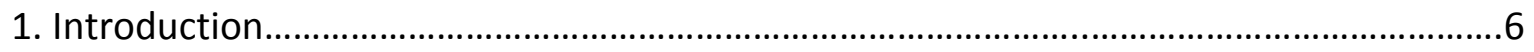

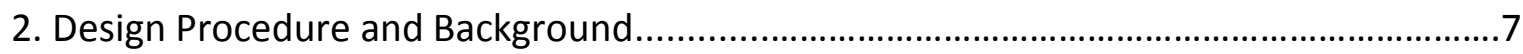

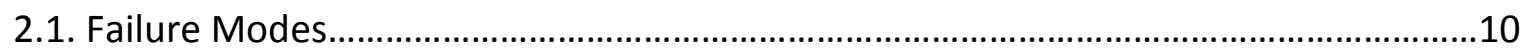

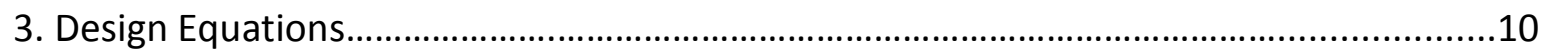

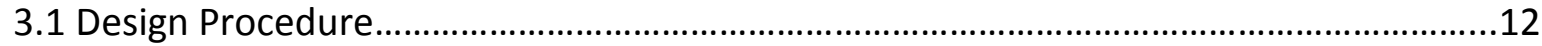

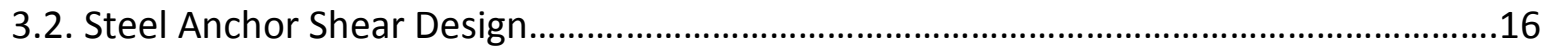

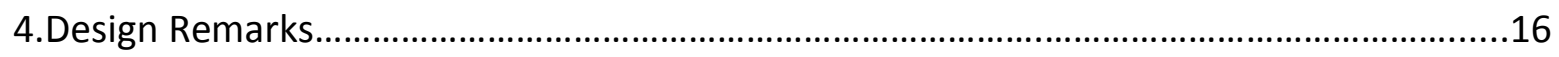

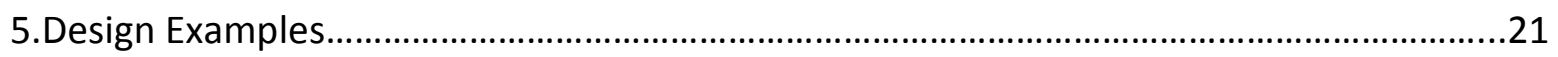

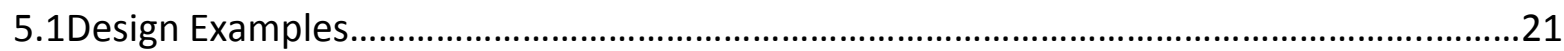

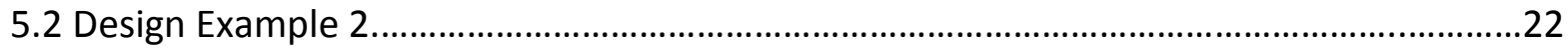

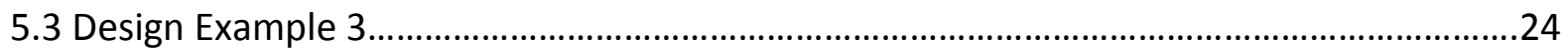

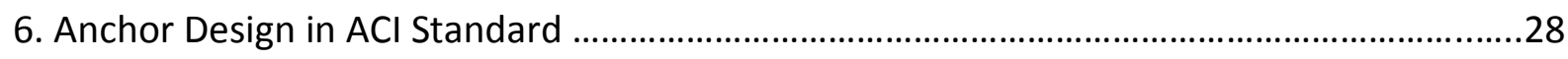

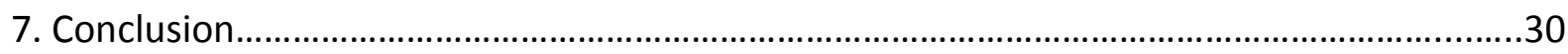

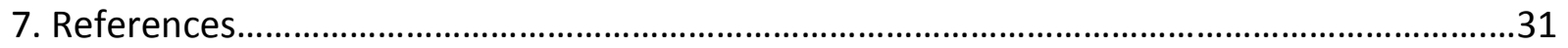




\section{List of Figures}

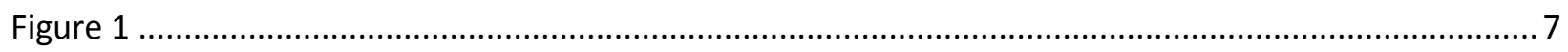

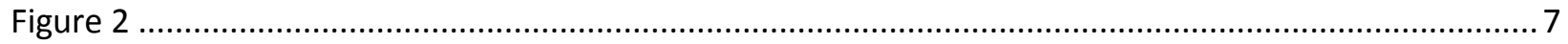

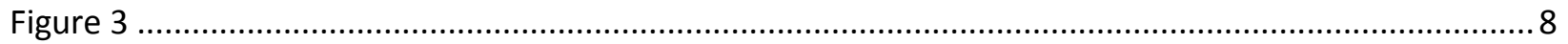

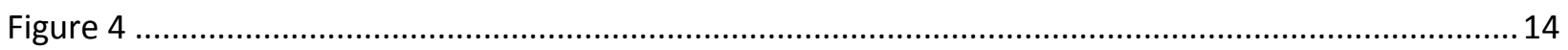

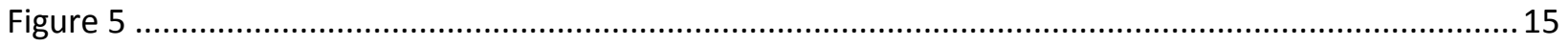

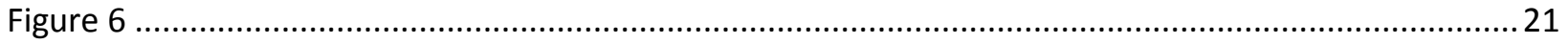

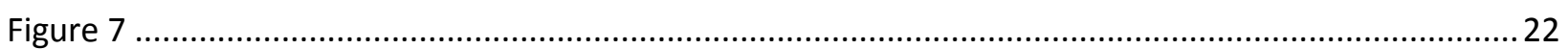

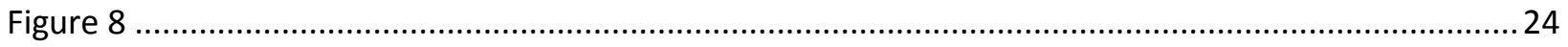

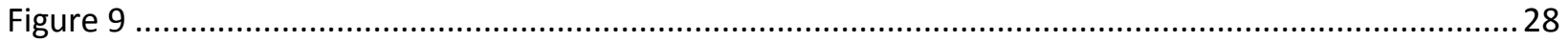




\section{List of Tables}

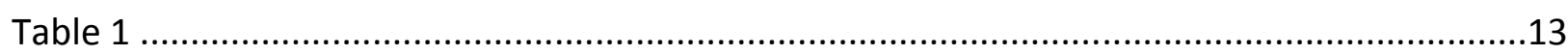

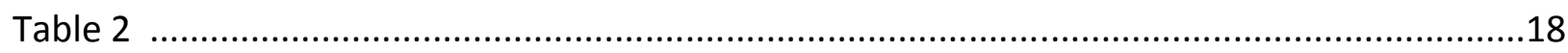

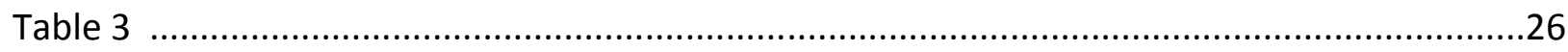

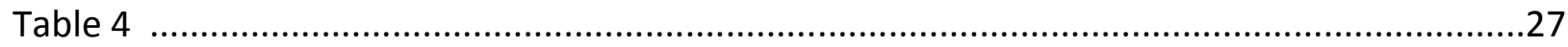




\section{AUTHOR'S DECLARATION}

I hereby declare that I am the sole author of this MENG Project. This is a true copy of the MENG Project, including any required final revisions.

I authorize Ryerson University to lend this MENG Project to other institutions or individuals for the purpose of scholarly research.

I further authorize Ryerson University to reproduce this MENG Project by photocopying or by other means, in total or in part, at the request of other institutions or individuals for the purpose of scholarly research.

I understand that my MENG Project may be made electronically available to the public.

Hamdi Kaan Kok 


\section{ABSTRACT}

This project is written in an informative manner and discusses design process, and requirements with examples for anchors and anchor groups in concrete which are used to transmit forces to concrete elements by tension, shear, or a combination of the two.

Various different anchor types, such as cast-in place anchors, post-installed anchors, adhesive anchors, expansion anchors, hooked bolts and undercut anchors are analyzed in this report. The critical effects of factored loads which the anchors and anchor groups are designed for, are determined by elastic analysis. Seismic effects which include load combinations with earthquake effects are out of this project's scope.

Discussed in this project, the background of theory, analytical analysis, and design equations provided in this project for determining the performance of a specific anchor have been calibrated from an extensive database of experimental tests which have been conducted over the last 30 years. The equations are designed with a $5 \%$ fractile failure level from these tests, meaning that 95 times out of 100 , the actual strength of the anchor will exceed the nominal strength which is key in providing a more consistent level of safety for a wider range of failure modes in both cracked and uncracked concrete.

In addition, this report also provides the design process of the same anchor types aforementioned, with design equations, in The American Concrete Institute codes. Key differences and similarities are paid particular attention to and discussed in depth compared to Canadian Standards in this report. 


\section{Introduction}

In reinforced concrete design anchor bolts are used to connect both structural and nonstructural members in to concrete. This report will focus on cast-in place anchors, post-installed expansion anchors, hooked bolts, undercut anchors and adhesive anchors. Cast-in place anchors are the simplest, and strongest type of anchor and comprised of either a hex head bolt with washer. Post-installed anchors can be installed in any position of hardened concrete after a drilling operation and they are divided into two based on their principle of operation. Torquecontrolled anchors are installed by applying a specific torque to the bolt head or nut with a torque wrench which causes a wedge being driven up a sleeve which expands and causes the anchor to compress against the material it is being fastened to. Displacement controlled anchors consist of an expansion sleeve and a conical expansion plug whereby the sleeve is internally threaded to accept a threaded element.

In undercut anchors, a special drilling operation helps create contact surface between the hole in the concrete and the anchor head for loads to transfer. Adhesive anchors consist of a special organic glue-like material that helps to transfer stresses. The anchoring material that binds the concrete into the bolt is an adhesive and it generally consists of epoxy, polyester, or vinyl ester resins. The main downside with adhesive anchors is that the performance in terms of load-bearing capacity depends on cleaning condition of the drilled hole. Through experiment it was found that a reduction of as much as $60 \%$ in tensile strength capacity was observed based on the condition of the hole as well as a reduction of $20 \%$ was observed if the hole in the concrete was wet. 


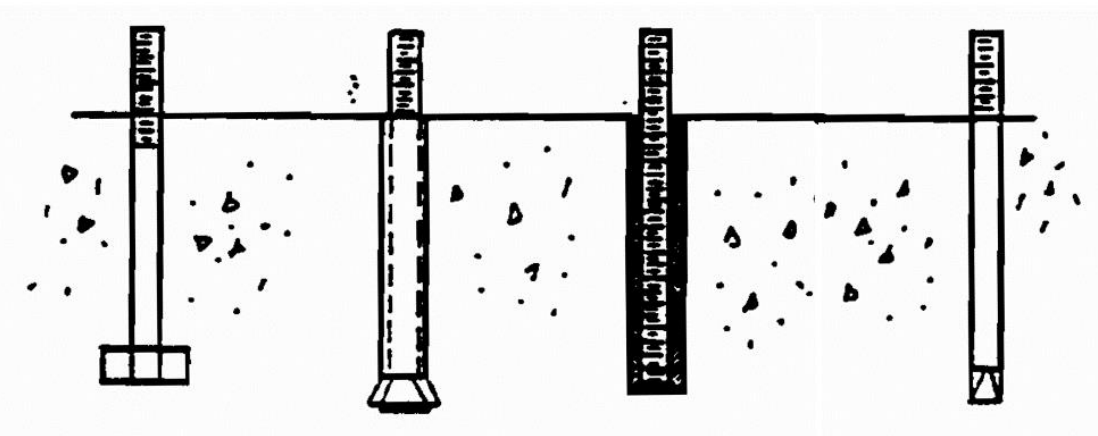

\section{Cast-in-Place Undercut Adhesive Expansion}

Figure 1

Anchor bolts transfer shear and tensile forces between different structural elements as seen from Figure 1. For all types of anchors, the load is transferred via mechanical interlock, the part of the anchor that is embedded in the concrete transfers the applied shear or axial load via bearing pressure at the contact zone. At failure conditions the bearing pressure can be in excess of ten times the concrete's compressive strength if a pure tension force is transferred.

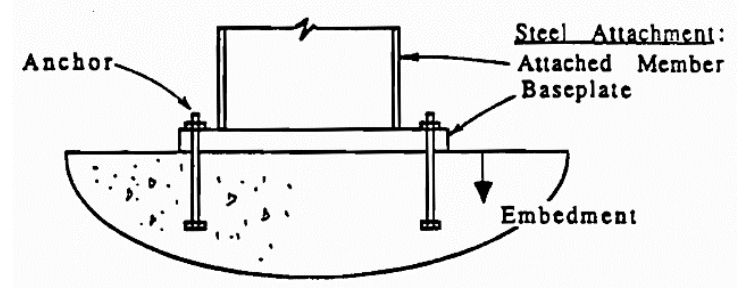

Figure 2

2. Design Procedure and Background

\section{1. $\quad$ Failure Modes}

When designing anchors, the capacity of the steel anchor as well as the concrete which the anchor is embedded into are the two main factors which need to be considered. The Concrete Capacity Design, CCD, method which is used in anchor design considers fracture mechanics to utilize a $35^{\circ}$ projected failure surface for the embedded portion of the anchor. In 
the CCD method, the capacity expressions have been determined according to extensive database of experimental tests that have been conducted for the past 30 years. A plastic approach requires the anchors to be installed in a way that promotes a brittle failure where concrete breakout occurs before steel yields which should be avoided unless a sufficient ductility is provided by the anchors that allows a redistribution of forces.

Concrete breakout failure mode occurs when the concrete which the anchor is embedded in cracks and fails resulting in the anchor being pulled out. This failure mode is brittle in nature and the concrete breakout cone is depicted in Figure 3 below. The concrete breakout capacity can be calculated from equation 1 seen below. Concrete pullout failure applies only to cast-in headed and hooked bolts. It occurs when the anchor does not have sufficient development length and results in the anchor being pulled out of the embedded concrete it is in. The pullout capacity of the anchor can be increased by using washers or plates which increases the bearing area. The pullout capacity of the anchor is calculated from equation 2.

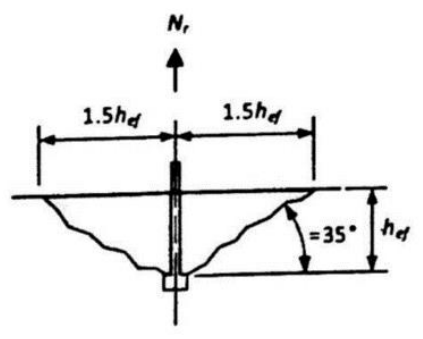

a) Breakout cone for tension

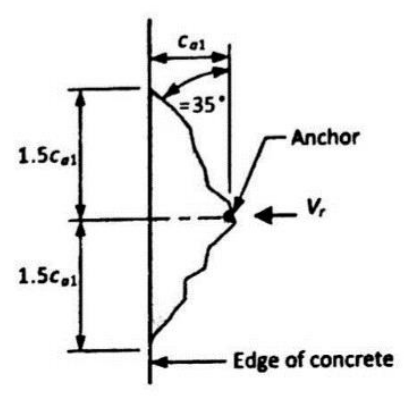

Plan view

b) Breakout cone for shear

Figure 3 
Steel failure mode is another form of failure and the most desirable one, since it is ductile in nature hence making it the safest. Steel failure occurs when the stresses in the anchor exceeds the ultimate stress steel can support causing it to yield and eventually rupture. According to Canadian standards where sufficient development length is provided on both sides of the breakout surface, the design strength of the anchor reinforcement may be used, as calculated from equation 3, instead of the concrete breakout strength. Anchor reinforcement comes from development length which is the minimum length required to develop the full tensile strength of the anchor. (Chalk Example) The thicker the anchor, the longer its' length has to be, the portion that is embedded in concrete in order to develop enough grip with the concrete. Side face blow out failure occurs when the lateral pressure which develops at the end which is embedded in the concrete exceeds the confining strength of the surrounding concrete. Equations 4 and 5 predict the side face blowout capacities for single and group anchors within a

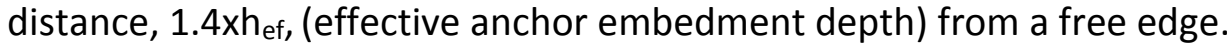

It should be noted that these equations are not applicable to $\mathrm{J}$ or $\mathrm{L}$ bolt anchors for which there are currently no formulas representing the side face blow out capacity. Therefore, designers are encouraged to use headed anchors in close proximity to free-edges. The capacity of adhesive anchors is calculated using Equation 6 where $N_{\text {bar }}$ represents the bond capacity of a single adhesive anchor without taking into consideration the cracking of the concrete, and edge effects. Bond capacity represents another failure type. It occurs when the bond provided by the adhesive anchor fails and causes the anchor to fail. In addition to the failure modes in tension an anchor can also fail in shear as well. The shear resistance of cast-in headed stud anchors is given by equation $\mathrm{V}_{\text {sar. }}$. This term represents the strength of the steel anchor in shear. Concrete breakout can also occur if the shear force in the anchor exceeds concrete's capacity which is represented in Equation 132. When an anchor is located near a corner, the designer is required to calculate the shear capacity in both orthogonal directions and use the lesser value. The final failure mode, concrete pry-out resistance. For cast-in anchors the pry-out resistance is equal to the tensile concrete breakout capacity for embedment depths less than $65 \mathrm{~mm}$ and twice that value for embedment depths greater than $65 \mathrm{~mm}$. 


\section{Design Equations}

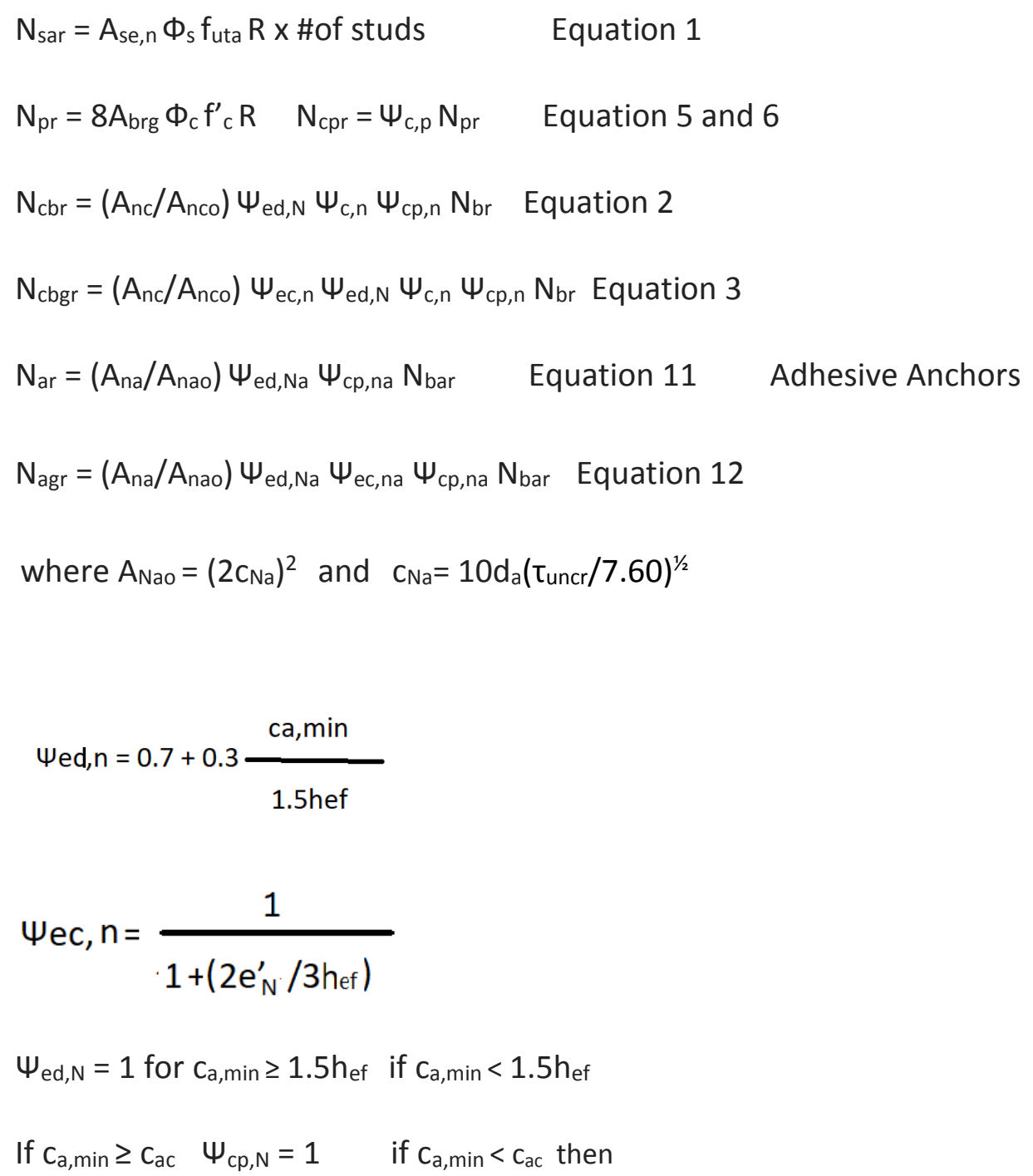




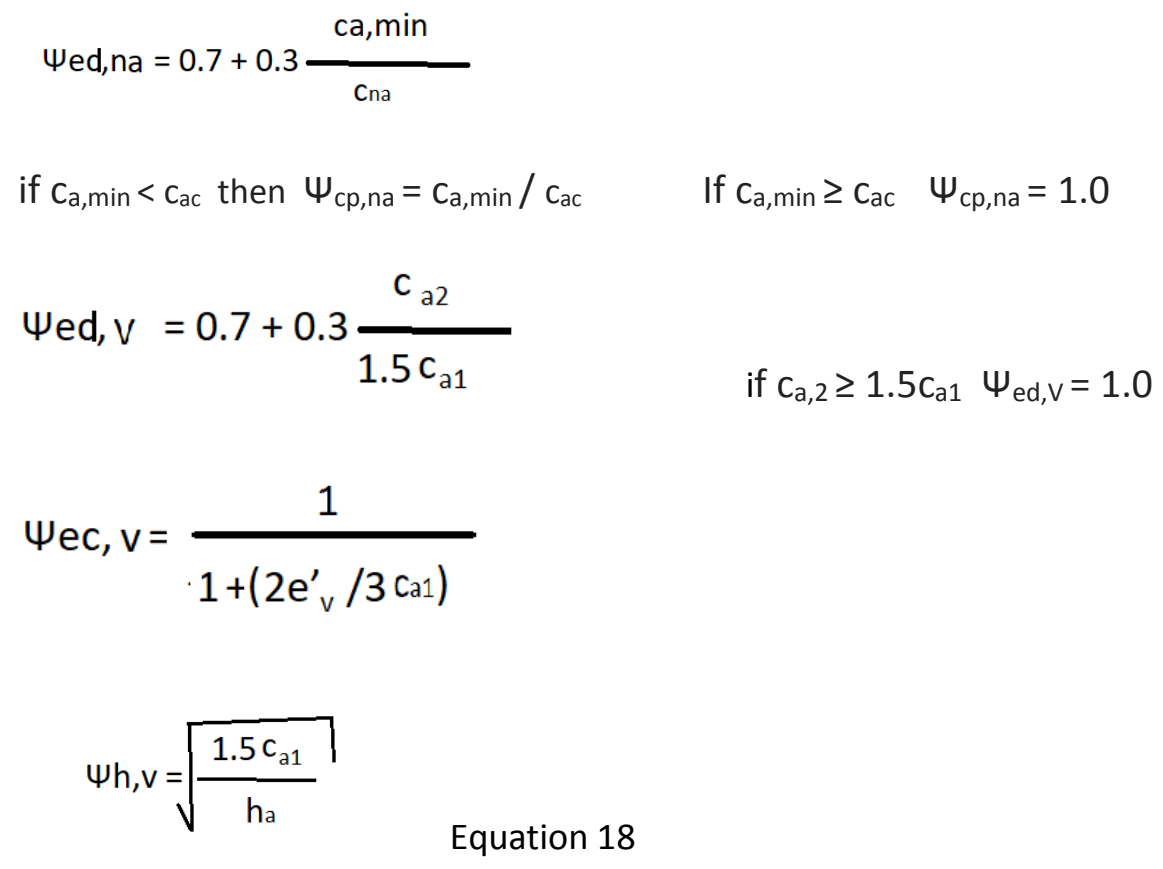

$\left(N_{f} / N_{r}\right)^{\mu}+\left(V_{f} / V_{r}\right)^{\mu} \leq 1.0$

$N_{b r}=k_{c} \Phi_{c} \lambda_{a}\left(f^{\prime}{ }_{c}\right)^{1 / 2}\left(h_{e f}\right)^{5 / 3} R \quad$ Equation 4

$N_{b r}=3.9 \Phi_{c} \lambda_{a}\left(f^{\prime}{ }_{c}\right)^{1 / 2}\left(h_{e f}\right)^{5 / 3} R \quad$ for $3 d_{a}<e_{n}<4.5 d_{a}$

$\mathrm{N}_{\mathrm{r}}=\mathrm{A}_{\mathrm{s}} \Phi_{\mathrm{s}} \mathrm{f}_{\mathrm{y}}^{\prime} R$

$N_{p r}=0.9 \Phi_{c} f^{\prime}{ }_{c} e_{n} d_{a} R \quad$ Equation $7 \quad$ (j-bolt) $d_{a}<h_{\text {ef }}<625 \mathrm{~mm}$

$N_{s b r}=13.3 c_{a 1} \lambda_{a} \Phi_{c}\left(A_{b r g}\right)^{1 / 2}\left(f^{\prime}{ }_{c}\right)^{1 / 2} R \quad$ Equation 8

$N_{s b g r}=\left(1+\frac{s}{6(c a 1)}\right) N s b r$

Equation 9

$\mathrm{V}_{\mathrm{sar}}=\mathrm{A}_{\mathrm{se}, \mathrm{v}} \Phi_{\mathrm{s}} \mathrm{f}_{\mathrm{uta}} \mathrm{R}$

$\mathrm{V}_{\mathrm{sar}}=0.6 \mathrm{~A}_{\mathrm{se}, \mathrm{v}} \Phi_{\mathrm{s}} \mathrm{f}_{\mathrm{uta}} \mathrm{R} \quad$ Equation 13

$V_{c b r}=\left(A_{v c} / A_{v c o}\right) \Psi_{e d, v} \Psi_{c, v} \Psi_{h, v} V_{b r} \quad$ Equation 14 


$$
\begin{aligned}
& \mathrm{V}_{\mathrm{cbgr}}=\left(\mathrm{A}_{\mathrm{vc}} / \mathrm{A}_{\mathrm{vco}}\right) \Psi_{\mathrm{ec}, \mathrm{n}} \Psi_{\mathrm{ed}, \mathrm{N}} \Psi_{\mathrm{c}, \mathrm{n}} \Psi_{\mathrm{cp}, \mathrm{n}} \mathrm{V}_{\mathrm{br}} \quad \text { Equation } 15 \\
& \mathrm{~V}_{\mathrm{br}}=0.58\left(\mathrm{l}_{\mathrm{e}} / \mathrm{d}_{\mathrm{a}}\right)^{0.2} \Phi_{\mathrm{c}} \lambda_{\mathrm{a}}\left(\mathrm{f}_{\mathrm{c}}^{\prime}\right)^{1 / 2}\left(\mathrm{c}_{\mathrm{a} 1}\right)^{1.5} \mathrm{R} \quad \text { Lesser Equation } 16 \\
& \mathrm{~V}_{\mathrm{br}}=3.75 \Phi_{\mathrm{c}} \lambda_{\mathrm{a}}\left(\mathrm{f}_{\mathrm{c}}^{\prime}\right)^{1 / 2}\left(\mathrm{c}_{\mathrm{a} 1}\right)^{1 / 2} \mathrm{R} \\
& \mathrm{A}_{\mathrm{vco}}=4.5\left(\mathrm{c}_{\mathrm{a} 1}\right)^{1 / 2} \\
& \mathrm{~V}_{\mathrm{r}}=\mathrm{A}_{\mathrm{s}} \Phi_{\mathrm{s}} \mathrm{f}_{\mathrm{y}}^{\prime} \mathrm{R} \\
& \mathrm{V}_{\mathrm{cpr}}=\mathrm{k}_{\mathrm{cp}} \mathrm{N}_{\mathrm{cbr}} \\
& \mathrm{V}_{\mathrm{cpgr}}=\mathrm{k}_{\mathrm{cp}} \mathrm{N}_{\mathrm{cpgr}}
\end{aligned}
$$

\subsection{Design Procedure}

The design process of an anchor consists of checking individually for each failure criteria for a headed stud and then taking the lowest strength as the governing failure mode. For example, if the anchor size is given, the tensile capacity of the steel stud is calculated first according to Equation 1. In that equation, the term $f_{\text {uta }}$ represents the specified tensile strength of the steel anchor. The term, R, is the resistance modification factor and and is rounded down, for anchors governed by ductile steel element it is 0.8 for tension and 0.7 for shear, for anchors governed by brittle steel element $R$ is 0.7 for tension and 0.65 for shear loads. If the failure mode is governed by concrete break-out, side face blow-out, pull-out or pry-out strength the $\mathrm{R}$ value according to CSA is given in the table below. The area $A_{s e, N}$ represents effective cross sectional area of anchor in tension. 


\begin{tabular}{|l|l|l|}
\hline & Condition A & Condition B \\
\hline Shear Loads & 1.15 & 1.0 \\
\hline Tension Loads & 1.15 & 1.0 \\
\hline Category 1 Post Installed Anchors & 1.15 & 1.0 \\
\hline Category 2 Post Installed Anchors & 1.0 & 0.85 \\
\hline Category 3 Post Installed Anchors & 0.85 & 0.75 \\
\hline
\end{tabular}

Table 1

The concrete break-out for tensile resistance is represented by equation 2 and 3 for individual and group anchors respectively for uncracked concrete. The term $A_{N c} / A_{N c o}$ accounts for presence of adjacent anchors and/or free edges. $A_{N c o}$ is the projected area of a $35^{\circ}$ failure plane of a single anchor measured relative to the surface of the concrete as depicted in Figure 4 $A_{N c}$ is a similarly projected area limited by edges and adjacent anchors. For single anchors located distant from free edges the $A_{N c} / A_{N c o}$ term equals to 1.0. $N_{b r}$ needs to be calculated first and it represents the factored concrete breakout resistance in tension of a single anchor in cracked concrete. $\mathrm{N}_{\mathrm{br}}$ is calculated according to equation 4 . The term $\mathrm{h}_{\mathrm{ef}}$ is the effective anchor embedment depth. The term $\lambda_{\mathrm{a}}$ is a factor to account low-density concrete in certain concrete anchorage applications and $\mathrm{k}_{\mathrm{c}}$ is a coefficient for factored concrete breakout resistance in tension. The $\Psi$ terms in equations 2 and 3 represent modification factors for various different criterias such as tensile strength based on proximity to edges, presence of cracks etc. 


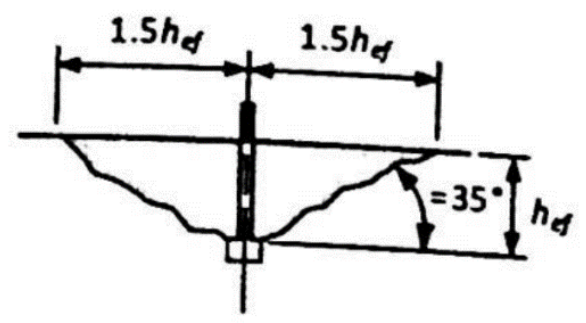

a) Section through failure cone

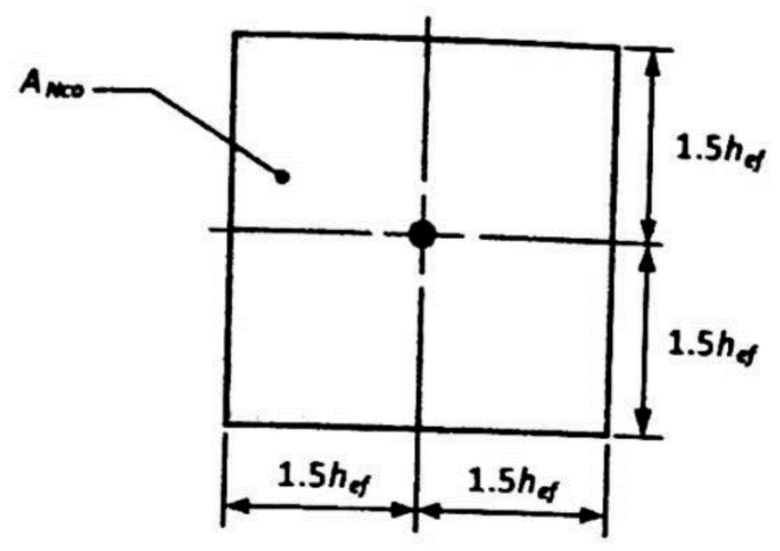

b) Plan view

Figure 4

The pull-out capacity equations in the handbook only apply to cast-in headed and hooked bolts only. Equations 5 and 6 are used to determine the cast-in anchors pull-out capacity. For hooked-bolts as seen in Figure 5, the expression to calculate the pull-out capacity is given in equation 7. 


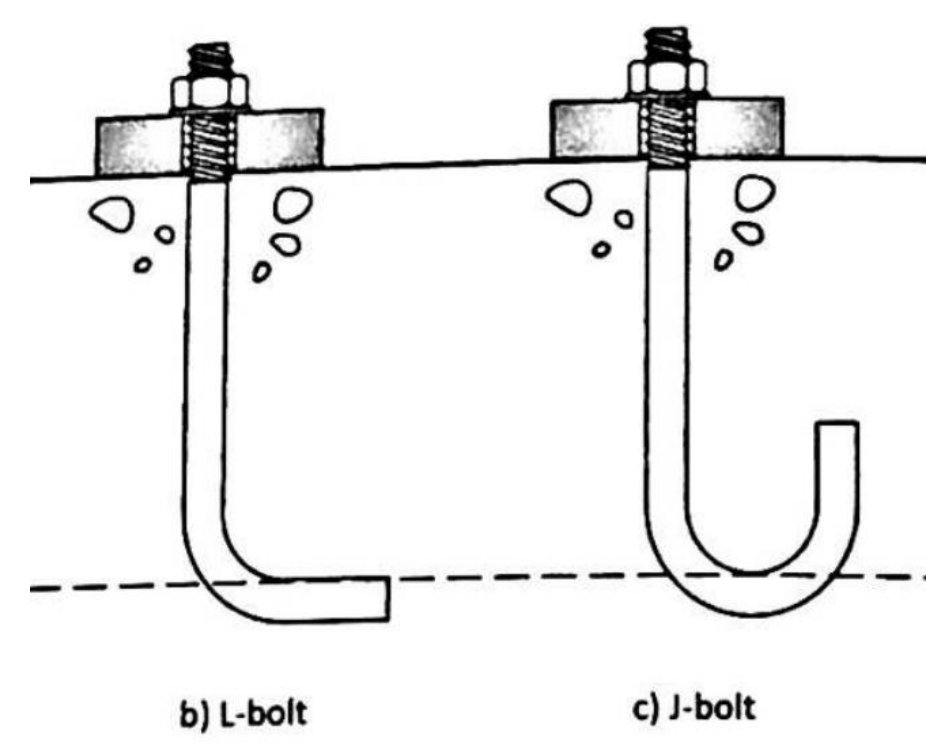

a) Cast-in anchors

Figure 5

Side-face blowout failure must be considered when $h_{\text {ef }} \geq 2.5 c_{a 1}$ where $c_{a 1}$ is the distance from the center of an anchor shaft to the edge of concrete in one direction and $\mathrm{h}_{\mathrm{ef}}$ is the effective embedment anchor depth. Equations 8 and 9 are used to predict the capacity for a side-face blowout. Edge distances greater than $0.4 \mathrm{~h}_{\text {ef }}$ are not required to be considered for side face blowout failure mode. The group effects are considered using equation 9 when the spacing between anchors is less than $6 c_{a 1}$. The term $s$ is distance between the outer anchors along the edge in a group. For $\mathrm{J}$ or $\mathrm{L}$ bolts these equations are not applicable for which there are currently no side face blowout expressions. Designers are encouraged to use headed anchors in close proximity to free edges.

For adhesive anchors, the expression for the factored resistance in tension is the same as the expression for cast-in place and mechanical post installed anchors and it is given in equations 11 and 12 both for single and group effects. $A_{\text {Nao }}$ is the projected influence area of a single adhesive anchor and $\mathrm{C}_{\mathrm{NaO}}$ is the projected distance from center of an anchor to develop the full bond strength of a single adhesive anchor. The factored bond resistance of a single 
adhesive anchor in tension for cracked concrete is given in Equation 10 . Equations 11 and 12 represent the factored bond resistance in tension for a single adhesive anchor and a group of adhesive anchors respectively. $A_{n a}$ is the projected influence area of a single adhesive anchor or group of adhesive anchors.

Anchor reinforcement is also a viable alternative when the concrete breakout capacity cannot be sufficiently utilized to develop the required shear capacity of the anchor. Clause D7.2.9 permits the use of anchor reinforcement and detailing is shown below in Figure 9. The performance of anchor reinforcement is governed by the location and detailing of the anchor reinforcement. In addition, the anchor reinforcement needs to be sufficiently developed on both sides of the concrete failure surface and/or be properly anchored beyond the breakout section.

\subsection{Steel Anchor Shear Design}

Similar to anchor design for tension, Clause D.7.1.2 limits $f_{\text {uta }}$ of the steel anchor to $1.9 f_{\text {ya }}$ in order to ensure the steel anchor does not yield under service loads. The main reason for this limit is because of anchor behaviour under stress, it does not exhibit a well defined yield point. The shear resistance of cast-in headed stud anchors is represented by Equation 13. $\Phi_{s}$ factor represents a $20 \%$ reduction in shear capacity as required by Clause D.7.1.3 which is due to the effect of flexural stresses that develop in the anchor if the supporting grout pad fractures under the applied shear load. $A_{s e, v}$ is included to represent the net cross-sectional area of either a single steel anchor or all the anchors in shear in a group.

The concrete breakout capacity in shear is represented, when the anchor is loaded in shear perpendicular to a free edge, for both single and group anchors respectively in Equations 14 and 15 . Similar to design in tension, a $35^{\circ}$ breakout prism angle is assumed. First, basic concrete breakout capacity is determined according to Equation 16 and then by applying additional factors which take into account cracking in concrete, group effects, eccentricity of loadings, and edge conditions. The term $A_{v c} / A_{v c o}$ represents the ratio of the shear breakout area of a group anchor arrangement versus the full shear breakout area of a single anchor 
unaffected by edge distance, spacing, or section depth. The term $\lambda_{a}$ represents additional strength reductions depending on the density of the concrete for certain anchor types and for bond resistance of adhesive anchors. The factor $\Psi_{\mathrm{ec}, \mathrm{v}}$ accounts for eccentric shear load application on an anchor group. The shear load is assumed to be oriented towards a free edge. If the edge distances limit the breakout area of the anchor in shear, additional reductions in the calculation of breakout strength of concrete must be taken into account. This is done using the factor $\Psi_{\text {ed,v. }} \Psi_{\mathrm{h}, \mathrm{v}}$ is a factor to take into account the fact that, reductions in shear strength for sections of limited depth is not directly proportional to the reduction in shear breakout area of the concrete. It is represented in Equation 18 and is always greater than or equal to 1.0.

The concrete pryout resistance for cast-in anchors has been found to be equal to the tensile concrete breakout capacity for embedment depths less than $65 \mathrm{~mm}$ and twice that value for embedment depths that are greater than $65 \mathrm{~mm}$. Lastly, the interaction effects for tensile and shear need to be considered and are represented in Equation 19. The term $\mu$ in the equation varies from 1.0 to 2.0. The provisions in Clause D.8 assume $\mu=5 / 3$. According to tests a tolerance of $20 \%$ can be accommodated before interaction effects need to be considered for cases involving both tension and shear effects.

\section{Design Remarks}

When designing anchors for tension and/or shear, special attention must be given to certain criterias which can directly impact the performance of an anchor. First and foremost Clause D.4.1.2 specifies when anchor group effects need to be considered. It states that whereever two or more anchors have spacing less than either $3 h_{e f} 2 c_{n a}$ and $3 c_{a 1}$. These three terms represent failure modes, concrete breakout strength in tension, bond strength in tension, and concrete breakout in shear respectively. Due to the upper limit on tests done on anchorage, the values of $\mathrm{f}^{\prime}{ }_{\mathrm{c}}$ used in calculations shall not exceed $70 \mathrm{MPa}$ for cast-in anchors and $55 \mathrm{MPa}$ for post-installed anchors. Additional testing is required for post-installed anchors used in concrete with $\mathrm{f}^{\prime}{ }_{\mathrm{c}}$ greater than $55 \mathrm{MPa}$. Anchor design must comply Table 1 as shown below. 


\begin{tabular}{|c|c|c|c|}
\hline \multirow[t]{2}{*}{ Failure Mode } & \multirow[t]{2}{*}{ Single Anchor } & \multicolumn{2}{|c|}{ Anchor Group } \\
\hline & & $\begin{array}{l}\text { Individual Anchor in } \\
\text { a Group }\end{array}$ & Anchors as a Group \\
\hline $\begin{array}{l}\text { Steel Strength in } \\
\text { Tension }\end{array}$ & $\mathrm{N}_{\mathrm{sar}} \geq \mathrm{N}_{\mathrm{fa}}$ & $\mathrm{N}_{\mathrm{sar}} \geq \mathrm{N}_{\mathrm{fa}, \mathrm{i}}$ & \\
\hline $\begin{array}{l}\text { Concrete Breakout } \\
\text { Strength in Tension }\end{array}$ & $\mathrm{N}_{\mathrm{cbr}} \geq \mathrm{N}_{\mathrm{fa}}$ & & $N_{c b g r} \geq N_{f a, g}$ \\
\hline $\begin{array}{l}\text { Pull-out Strength in } \\
\text { Tension }\end{array}$ & $\mathrm{N}_{\mathrm{pr}} \geq \mathrm{N}_{\mathrm{fa}}$ & $\mathrm{N}_{\mathrm{pr}} \geq \mathrm{N}_{\mathrm{fa}, \mathrm{i}}$ & \\
\hline $\begin{array}{l}\text { Concrete Side-Face } \\
\text { Blowout Strength in } \\
\text { Tension }\end{array}$ & $\mathrm{N}_{\mathrm{sbr}} \geq \mathrm{N}_{\mathrm{fa}}$ & & $N_{\text {sbgr }} \geq N_{f a, g}$ \\
\hline $\begin{array}{l}\text { Bond Strength of } \\
\text { Adhesive Anchor in } \\
\text { Tension }\end{array}$ & $\mathrm{N}_{\mathrm{ar}} \geq \mathrm{N}_{\mathrm{fa}}$ & & $N_{a g r} \geq N_{f a, g}$ \\
\hline $\begin{array}{l}\text { Steel Strength in } \\
\text { Shear }\end{array}$ & $V_{s a r} \geq V_{f a}$ & $\mathrm{~V}_{\mathrm{sar}} \geq \mathrm{V}_{\mathrm{fa}}$ & \\
\hline $\begin{array}{l}\text { Concrete Breakout } \\
\text { Strength in Shear }\end{array}$ & $\mathrm{V}_{\mathrm{cbr}} \geq \mathrm{V}_{\mathrm{fa}}$ & & $V_{\text {cbgr }} \geq V_{f a, g}$ \\
\hline $\begin{array}{l}\text { Concrete Pry-out } \\
\text { Strength in Shear }\end{array}$ & $\mathrm{V}_{\mathrm{cpr}} \geq \mathrm{V}_{\mathrm{fa}}$ & & $\mathrm{V}_{\mathrm{cpr}} \geq \mathrm{V}_{\mathrm{fa}}$ \\
\hline
\end{tabular}

Table 2

The concrete breakout strength for both tension and shear is not required and can be ignored provided that the anchor has sufficient development length, and anchor reinforcement is provided in accordance with the standards. The factor $\Psi_{c p, n}$ represents modification for uncracked concrete. In cracked concrete it equals 1.0 however for uncracked concrete it is calculated according to Equation 19 if $c_{a, \min }<c_{a c}$. For all other cases $\Psi_{c p, n}$ equals 1.0. If an additional washer or a plate is added at the head of the anchor, the projected area of the 
failure surface may be calculated by projecting the failure surface outward $1.5 \mathrm{~h}_{\text {ef }}$ from the effective perimeter of the washer.

When calculating the pullout capacity of a cast-in anchor in uncracked concrete at service load levels, a modifiction factor of $\Psi_{c, p}=1.4$ may be used. It should also be noted that if a second orthogonal free edge $c_{a 2}$ is within $3 c_{a 1}$ of the anchor, like a corner, Clause D.6.4 reduces the side face blowout strength further by up to $50 \%$ as dimension $c_{a 2}$ reduces from $3 c_{a 1}$ to $c_{a 1}$. This reduction factor is represented as $\left(1+c_{a 2} / c_{a 1}\right) / 4$.

When designing anchors for shear special attention must be paid when the threads in the steel anchor intercept the shear plane, the effective area of the anchor should be taken as being $0.7 \mathrm{Ag}_{\mathrm{g}}$. Although this is not explicitly stated in Clause D.7.1.2 CSA Standards require 70\% of the gross area be taken as the effective net area $A_{\text {se }}$ for threaded bolts. It should also be noted that many post-installed anchors with expansion mechanisms have reduced cross-sectional areas. When this is the case designer should always follow the cross-sectional area data supplied by the manufacturer.

When calculating the concrete breakout in shear, where shear acts parallel to a free edge, Clause D.7.2.1(c) limits the shear force to a maximum value twice the capacity determined for shear forces acting perpendicular to the edge. However, when an anchor is located near a corner, the designer is required to evaluate the shear capacity in both orthogonal directions and limit the shear load to the lesser of the two. For anchor groups, if the anchors are spaced far enough such that their failure surfaces do not intersect then two possible failure conditions should be investigated. If the two anchors are not rigidly connected than the front anchor possesses a smaller failure surface making it the critical condition. In the case where the two anchors are rigidly connected, the shear capacity will be connected by the back anchor. When the front anchor begins to break out, the entire shear load is transferred to the back anchor. Since the back anchor will now carry the entire load, the critical failure surface will become the break-out section associated with that anchor.

Anchors' shear stiffness ratio $\mathrm{l}_{\mathrm{e}} / \mathrm{d}_{\mathrm{a}}$ is limited to 8.0 due to the extent of the tests done. Anchors with a larger shear stiffness ratio are able to transfer the shear load over a greater 
depth in the concrete, providing a greater shear resistance. Also when calculating the factor $\Psi_{c, v}$ it is taken as 1.0 if cracking analysis has not been conducted and no reinforcement has provided to control the cracking. If the concrete has been determined that it will remain uncracked at service load levels, this factor $\Psi_{c, v}$ is equal to 1.4 , providing a $40 \%$ increase in shear capacity of the anchor. 


\section{Design Examples}

\subsection{Example 1 Tension Capacity with No Edge Effects}

What is the maximum factored tensile capacity of the single AWS D1.1 welded stud anchor shown below? Assume the stud is distant from any edges, the normal density concrete is cracked at service loads, and no supplemental reinforcement is used.

Assume $f^{\prime}{ }^{\prime}=30 \mathrm{MPa} \quad \Phi_{\mathrm{c}}=0.65 \quad \Phi_{\mathrm{s}}=0.85 \quad \mathrm{~h}_{\mathrm{ef}}=125 \mathrm{~mm} \quad \mathrm{f}_{\mathrm{ya}}=344 \mathrm{MPa} \quad \mathrm{f}_{\mathrm{uta}}=414 \mathrm{MPa}$

Shank diameter $=d_{a}=15.7 \mathrm{~mm}$

Head diameter $\mathrm{d}_{\text {head }}=25.4 \mathrm{~mm}$

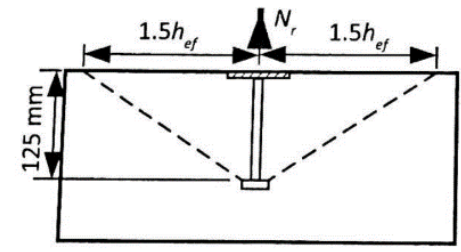

$\mathrm{R}=0.8$ (ductile steel loaded in tension)

Figure 6

$A_{s e, n}=(\pi / 4) d^{2}=(\pi / 4) 15.7^{2}=193 \mathrm{~mm}^{2}$

$\mathrm{N}_{\text {sar }}=A_{\text {se }, n} \Phi_{s} f_{\text {uta }} R=193 \times 0.85 \times 414 \times 0.8=54333 \mathrm{~N}$

Check concrete's breakout capacity $\mathrm{R}=1.0$

$N_{b r}=k_{c} \Phi_{c} \lambda_{a}\left(f^{\prime}\right)^{1 / 2}\left(h_{e f}\right)^{5 / 3} R \quad \lambda_{a}=1.0 \quad R=1.0 \quad k_{c}=10$ for cast-in headed studs

$\mathrm{N}_{\mathrm{br}}=10 \times 0.65 \times 1 \times(30)^{1 / 2} \times(125)^{5 / 3} \times 0.8=49755 \mathrm{~N}$

$\mathrm{N}_{\mathrm{cbr}}=\left(\mathrm{A}_{\mathrm{nc}} / \mathrm{A}_{\mathrm{nco}}\right) \Psi_{\mathrm{ed}, \mathrm{N}} \Psi_{\mathrm{c}, \mathrm{n}} \Psi_{\mathrm{cp}, \mathrm{n}} \mathrm{N}_{\mathrm{br}}$

$A_{n c}=A_{n c o}=9\left(h_{e f}\right)^{2}=9(125)^{2}=140625 \mathrm{~mm}^{2} \quad$ (the anchor is distant from all edges)

$\Psi_{\text {ed,N }}=1.0$ (the anchor is distant from all edges)

$\Psi_{c, n}=1.0 \quad$ (cracked concrete)

$\Psi_{\mathrm{cp}, \mathrm{n}}=1.0 \quad$ (not applicable, taken as 1.0 for cast-in anchors)

$\mathrm{N}_{\mathrm{cbr}}=1 \times 1 \times 1 \times 1 \times 49755=49755 \mathrm{~N}$

Check concrete's pullout capacity

$N_{p r}=8 A_{b r g} \Phi_{c} f_{c}^{\prime} R$

$A_{\text {brg }}=(\pi / 4)\left(d^{2}\right.$ head $\left.-d^{2}{ }_{a}\right)=(\pi / 4)\left(25.4^{2}-15.7^{2}\right)=313 \mathrm{~mm}^{2}$

$R=1.0$ (for pullout capacity always assume condition B) 
$\mathrm{N}_{\mathrm{pr}}=8 \times 313 \times 0.65 \times 30 \times 1=48843 \mathrm{kN}$

For cracked concrete $\quad \Psi_{c, p}=1.0$

$\mathrm{N}_{\mathrm{cpr}}=\Psi_{\mathrm{c}, \mathrm{p}} \mathrm{N}_{\mathrm{pr}}=1.0 \times 48843=48843 \mathrm{~N}$

Least capacity governs therefore maximum factored tensile capacity: $\mathbf{N}_{\mathrm{cpr}}=\mathbf{4 8 . 8} \mathbf{~ k N}$

\subsection{Example 2 Shear Capacity with No Edge Effects}

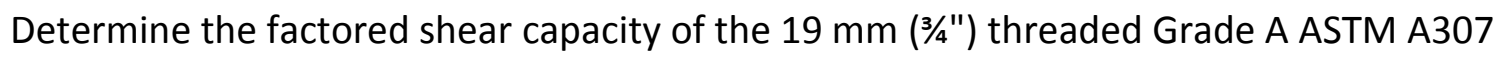
anchor shown. Assume uncracked $30 \mathrm{MPa}$ concrete with $\mathrm{f}_{\mathrm{ya}}=250 \mathrm{MPa}, \mathrm{f}_{\mathrm{uta}}=414 \mathrm{MPa}$, and normal density concrete.

$f_{\text {uta }} / f_{\text {ya }}=1.65<1.9$ passes the check

$V_{\text {sar }}=0.6 A_{s e, v} \Phi_{s} f_{\text {uta }} R$

$R=0.75$ for ductile steel anchor loaded in shear

$A_{s e, v}=0.7\left(A_{g}\right)=0.7\left(\pi d^{2}\right)=0.7\left(\pi \times 19^{2}\right)=198 \mathrm{~mm}^{2}$

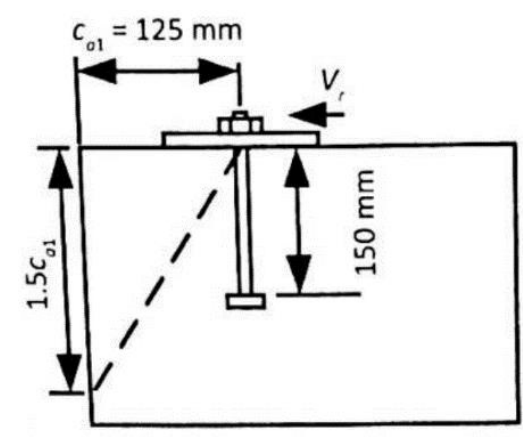

Figure 7

$\mathrm{V}_{\mathrm{sar}}=0.6 \times 198 \times 0.85 \times 414 \times 0.75=31.354 \mathrm{kN}$

Check the concrete's breakout capacity in shear

$\mathrm{V}_{\mathrm{cbr}}=\left(\mathrm{A}_{\mathrm{vc}} / \mathrm{A}_{\mathrm{vco}}\right) \Psi_{\mathrm{ed}, \mathrm{v}} \Psi_{\mathrm{c}, \mathrm{v}} \Psi_{\mathrm{h}, \mathrm{v}} \mathrm{V}_{\mathrm{br}}$

Where $V_{b r}=0.58\left(l_{e} / d_{a}\right)^{0.2} \Phi_{c} \lambda_{a}\left(f_{c}^{\prime}\right)^{1 / 2}\left(c_{a 1}\right)^{1.5} R$

$l_{e} / d_{a}=150 / 19=7.89<8$ therefore it is good!

$R=1.0$ for shear load without supplementary reinforcement, i.e. condition B

$\lambda_{a}=1.0$ for normal density concrete

$\mathrm{C}_{\mathrm{a} 1}=125 \mathrm{~mm}$ as seen from the figure 
$V_{b r}=0.58 \times(7.89)^{0.2} \times 0.65 \times 1 \times(30)^{1 / 2} \times(125)^{1.5} \times 1=19012 \mathrm{~N}$

$\Psi_{\text {ed, }}=1.0$ (no edge effects considered)

$\Psi_{c, v}=1.4$ assume concrete is uncracked at service loads

$$
\begin{aligned}
& \Psi h, v=\sqrt{\frac{1.5 \mathrm{c}_{\mathrm{a} 1}}{\mathrm{~h}_{\mathrm{a}}}} \\
& \Psi_{\mathrm{h}, \mathrm{v}}=((1.5 \times 125) / 200)^{1 / 2}=0.98 \text { but } \Psi_{\mathrm{h}, \mathrm{v}} \geq 1.0 \text { therefore use } 1.0 \\
& \mathrm{~V}_{\mathrm{cbr}}=1.0 \times 1.0 \times 1.4 \times 1.0 \times 19.0=26.6 \mathrm{kN} \\
& \text { Check the pryout capacity } \\
& \mathrm{V}_{\mathrm{cpr}}=\mathrm{k}_{\mathrm{cp}} \mathrm{N}_{\mathrm{cbr}} \quad \text { where } \mathrm{k}_{\mathrm{cp}}=2.0 \text { for } \mathrm{h}_{\mathrm{ef}} \geq 65 \mathrm{~mm} \text { pryout capacity is taken as twice } \\
& \text { the tensile breakout capacity } \\
& \mathrm{N}_{\mathrm{cbr}}=\left(\mathrm{A}_{\mathrm{nc}} / \mathrm{A}_{\mathrm{nco}}\right) \Psi_{\mathrm{ed}, \mathrm{N}} \Psi_{\mathrm{c}, \mathrm{n}} \Psi_{\mathrm{cp}, \mathrm{n}} \mathrm{N}_{\mathrm{br}} \\
& A_{N c}=\left(125+1.5 h_{e f}\right) \times 3 h_{e f}=(125+(1.5 \times 150)) \times 3 \times 150=157500 \mathrm{~mm}^{2} \\
& A_{n c o}=9 h^{2}{ }_{e f}=9 \times 150^{2}=202500 \mathrm{~mm}^{2} \\
& \Psi \text { ed, } n=0.7+0.3 \frac{\mathrm{ca}_{\text {, } \min }}{1.5 \mathrm{hef}} \quad \text { if } \mathrm{c}_{\mathrm{a}, \mathrm{min}}<1.5 \mathrm{~h}_{\mathrm{ef}} \\
& \Psi_{\text {ed,N }}=0.7+0.3(125 /(1.5 \times 150))=0.867 \\
& \Psi_{c, n}=1.25 \text { for uncracked concrete } \\
& \Psi_{\mathrm{cp}, \mathrm{n}}=1.0 \text { for cast-in-place anchor } \\
& \mathrm{N}_{\mathrm{br}}=\mathrm{k}_{\mathrm{c}} \Phi_{\mathrm{c}} \lambda_{\mathrm{a}}\left(\mathrm{f}_{\mathrm{c}}\right)^{1 / 2}\left(\mathrm{~h}_{\mathrm{ef}}\right)^{5 / 3} \mathrm{R} \quad \mathrm{R}=1.0 \mathrm{k}_{\mathrm{c}}=10 \text { for cast-in headed studs } \\
& \mathrm{N}_{\mathrm{br}}=10 \times 0.65 \times 1 \times(30)^{1 / 2} \times(150)^{1.5} \times 1.0=65404 \mathrm{~N} \\
& \mathrm{~N}_{\mathrm{cbr}}=(157500 / 202500)(0.867) \times 1.25 \times 1.0 \times 65404=55100 \mathrm{~N} \\
& \mathrm{~V}_{\mathrm{cpr}}=\mathrm{k}_{\mathrm{cp}} \mathrm{N}_{\mathrm{cbr}}=2 \times 55100=110200 \mathrm{~N}=110.2 \mathrm{kN}
\end{aligned}
$$


Least capacity governs therefore maximum factored shear capacity: $\mathbf{V}_{\mathbf{c b r}}=\mathbf{2 6 . 6} \mathbf{~ k N}$

\subsection{Example 3 Group of Headed Studs in Tension Near an Edge}

Design a group of four AWS D1.1 Type B welded headed studs spaced $150 \mathrm{~mm}$ center to center each way and eccentrically loaded with a factored load, $\mathrm{N}_{\mathrm{f}}=45 \mathrm{kN}$. Assume $\mathrm{f}_{\mathrm{c}}=30 \mathrm{MPa}$ $\Phi_{c}=0.65 \Phi_{s}=0.85$ and ductile steel $\mathrm{f}_{\mathrm{uta}}=414 \mathrm{MPa} \mathrm{f}_{\mathrm{uta}} / \mathrm{f}_{\mathrm{ya}}<1.9$.
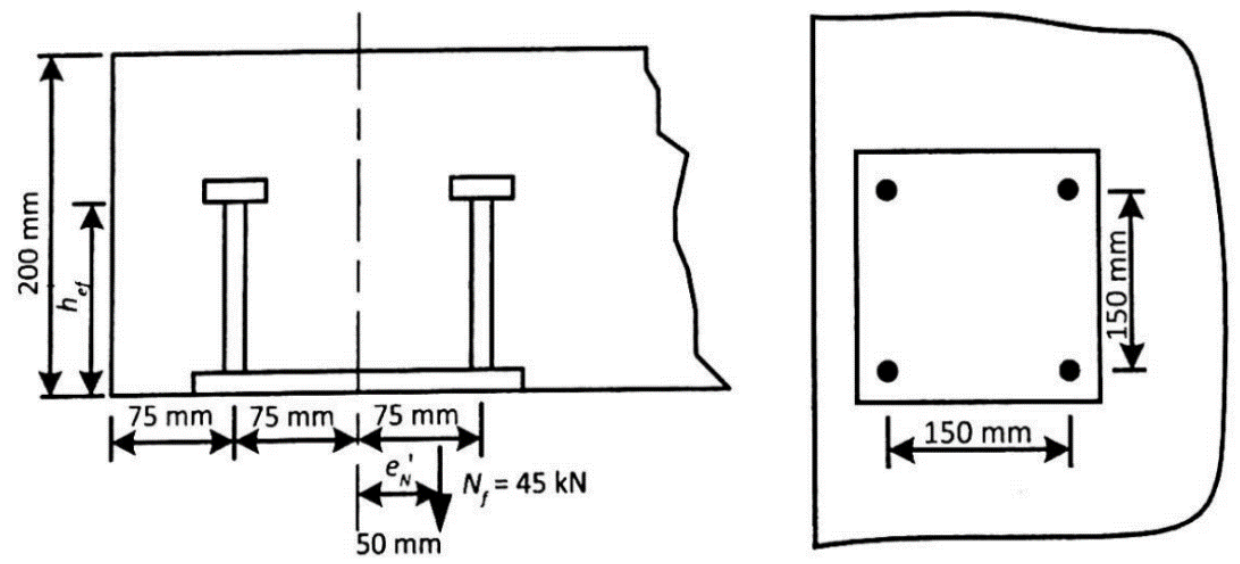

Figure 8

As seen from the above figure, the load is applied eccentrically. Due to this eccentricity, in order to find the load in each anchor, sum moments about the left anchor and solve for the force in right anchor. Then divide this number by 2 since there are two interior studs for conservative design to get $\mathrm{N}_{\text {sar. }}$.

Right Anchor $=45 x(75+50) /(75+75)=37.5 \mathrm{kN} \quad \mathrm{N}_{\mathrm{sar}}=37.5 / 2=18.7 \mathrm{kN}$

$\mathrm{N}_{\text {sar }}=18700=A_{s e, n} \Phi_{s} f_{\text {uta }} R=0.85 \times 0.8 \times 414 \times A_{s e, n} \quad A_{s e, n}=66.4 \mathrm{~mm}^{2}$

From Table 3 below select an anchor size keeping in mind that the anchor will also need to resist the pullout force as well. $1 / 2$ " diameter stud with $A_{s e, n}=127 \mathrm{~mm}^{2}$ is selected. 
Provided: $\mathrm{N}_{\mathrm{sar}}=\mathrm{A}_{\mathrm{se}, \mathrm{n}} \Phi_{\mathrm{s}} \mathrm{f}_{\text {uta }} \mathrm{R}$ x\#of studs $=127 \times 0.85 \times 414 \times 0.8 \times 4=143012 \mathrm{~N}>\mathrm{N}_{\mathrm{f}}$

$$
\begin{aligned}
& N_{c b g r}=\left(A_{n c} / A_{n c o}\right) \Psi_{e c, n} \Psi_{e d, N} \Psi_{c, n} \Psi_{c p, n} N_{b r} \\
& A_{n c}=\left(75+150+1.5 h_{e f}\right) \times\left(1.5 h_{e f}+150+1.5 h_{e f}\right)=(75+150+172) \times(172+150+172) \\
& =196118 \mathrm{~mm}^{2}
\end{aligned}
$$

$A_{n c o}=9 h^{2}{ }_{\text {ef }}=9(115)^{2}=119205 \mathrm{~mm}^{2}$ (failure surface without edge effects)

$4 \times 119205=476280>196118 \mathrm{~mm}^{2} \quad$ Passes check for group effect

Calculate the coefficient for eccentricity

$$
\begin{aligned}
& \Psi \text { ec, } n=\frac{1}{1+\left(2 e_{N}^{\prime} / 3 h_{e f}\right)} \\
& \Psi_{\mathrm{ec}, \mathrm{n}}=1 /(1+(2(50) / 3 \times 115))=0.775
\end{aligned}
$$

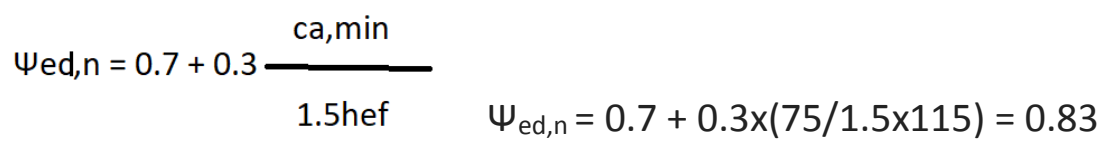

$$
\begin{aligned}
& \Psi_{c, n}=1.0 \text { for for cracked concrete } \\
& \Psi_{\mathrm{cp}, \mathrm{n}}=1.0 \text { for cast-in anchors } \\
& \mathrm{N}_{\mathrm{br}}=\mathrm{k}_{\mathrm{c}} \Phi_{\mathrm{c}} \lambda_{\mathrm{a}}\left(\mathrm{f}_{\mathrm{c}}\right)^{1 / 2}\left(\mathrm{~h}_{\mathrm{ef}}\right)^{3 / 2} \mathrm{R} \quad \mathrm{R}=1.0 \mathrm{k}_{\mathrm{c}}=10 \text { for cast-in headed studs } \\
& \mathrm{N}_{\mathrm{br}}=10 \times 0.65 \times 1 \times(30)^{1 / 2} \times(115)^{1.5} \times 1.0=43.9 \mathrm{kN} \\
& N_{c b g r}=\left(A_{n c} / A_{n c o}\right) \Psi_{e c, n} \Psi_{e d, N} \Psi_{c, n} \Psi_{c p, n} N_{b r} \\
& \mathrm{~N}_{\mathrm{cbgr}}=(119118 / 119025)(0.775 \times 0.83 \times 1.0 \times 1.0) 43.9=46.4 \mathrm{kN}>\mathrm{N}_{f}=45 \mathrm{kN}
\end{aligned}
$$

Check the pull-out capacity $\mathrm{N}_{\text {pr }}$ for the two most heavily loaded studs.

$A_{b r g}=380 \mathrm{~mm}^{2}$ for $1 / 2$ " diameter studs with a 1 " diameter head

$$
\begin{aligned}
& N_{p r}=8 A_{b r g} \Phi_{c} f_{c}^{\prime} R \\
& N_{p r}=8 \times 380 \times 0.65 \times 30 \times 1.0=59280 \mathrm{~N}>18700 \mathrm{~N} \text { passes the check! }
\end{aligned}
$$


Least capacity governs therefore maximum factored tensile capacity:

$N_{c b g r}=46.4 \mathrm{kN}>N_{f}=45 \mathrm{kN}$ which is sufficient to support the factored eccentric load.

\begin{tabular}{|c|l|c|c|}
\hline Anchor Diameter (in) & $\begin{array}{c}\text { Gross Area of anchor } \\
\left(\mathrm{in}^{2}\right)\end{array}$ & $\begin{array}{c}\text { Effective Area of } \\
\text { Anchor } \mathrm{A}_{\mathrm{se}, \mathrm{N}}\left(\mathrm{in}^{2}\right)\end{array}$ & $\begin{array}{c}\text { Bearing Area of Hex } \\
\text { Nut } \mathrm{Abrg}_{\mathrm{brg}}\left(\mathrm{in}^{2}\right)\end{array}$ \\
\hline 0.25 & 0.049 & 0.032 & 0.117 \\
\hline 0.375 & 0.11 & 0.078 & 0.164 \\
\hline 0.5 & 0.196 & 0.142 & 0.291 \\
\hline 0.625 & 0.307 & 0.226 & 0.454 \\
\hline 0.75 & 0.442 & 0.334 & 0.654 \\
\hline 0.875 & 0.601 & 0.462 & 0.891 \\
\hline 1 & 0.785 & 0.606 & 1.163 \\
\hline 1.125 & 0.994 & 0.763 & 1.472 \\
\hline 1.25 & 1.227 & 0.969 & 1.817 \\
\hline 1.375 & 1.485 & 1.16 & 2.199 \\
\hline 1.5 & 1.767 & 1.41 & 2.617 \\
\hline 1.75 & 2.405 & 1.9 & 4.144 \\
\hline 2 & 3.142 & 2.5 & 5.316 \\
\hline
\end{tabular}

Table 3 


\begin{tabular}{|c|c|c|c|}
\hline $\begin{array}{l}\text { Anchor Diameter } \\
(\mathrm{mm})\end{array}$ & $\begin{array}{l}\text { Gross Area of anchor } \\
\qquad\left(\mathrm{mm}^{2}\right)\end{array}$ & $\begin{array}{c}\text { Effective Area of } \\
\text { Anchor } A_{s e, N}\left(\mathrm{~mm}^{2}\right)\end{array}$ & $\begin{array}{l}\text { Bearing Area of Hex } \\
\text { Nut } A_{b r g}\left(\mathrm{~mm}^{2}\right)\end{array}$ \\
\hline 6.35 & 32 & 21 & 108 \\
\hline 9.525 & 71 & 50 & 193 \\
\hline 12.7 & 127 & 92 & 301 \\
\hline 15.875 & 198 & 146 & 433 \\
\hline 19.05 & 285 & 215 & 588 \\
\hline 22.225 & 388 & 298 & 766 \\
\hline 25.4 & 507 & 391 & 968 \\
\hline 28.575 & 641 & 492 & 1194 \\
\hline 31.75 & 792 & 625 & 1443 \\
\hline 34.935 & 959 & 748 & 1715 \\
\hline 38.1 & 1140 & 910 & 2012 \\
\hline 44.45 & 1552 & 1226 & 2674 \\
\hline 50.8 & 2027 & 1613 & 3430 \\
\hline
\end{tabular}

Table 4 


\section{Anchor Design in ACl Standard}

Similar to the Canadian Codes, the design process of an anchor in ACl Standards consists of checking individually for each failure criteria for a headed stud and then taking the lowest strength as the governing failure mode. Similar to the Canadian Code, ACl Standards use the Concrete Capacity Design, CCD, method which considers fracture mechanics to utilize a $35^{\circ}$ projected failure surface for the embedded portion of the anchor. This failure plane can be seen below in Figure 9. The design formulas in the two codes appear similar to each other in that both use elastic analysis in determining critical effects of factored loads in anchor and anchor groups.

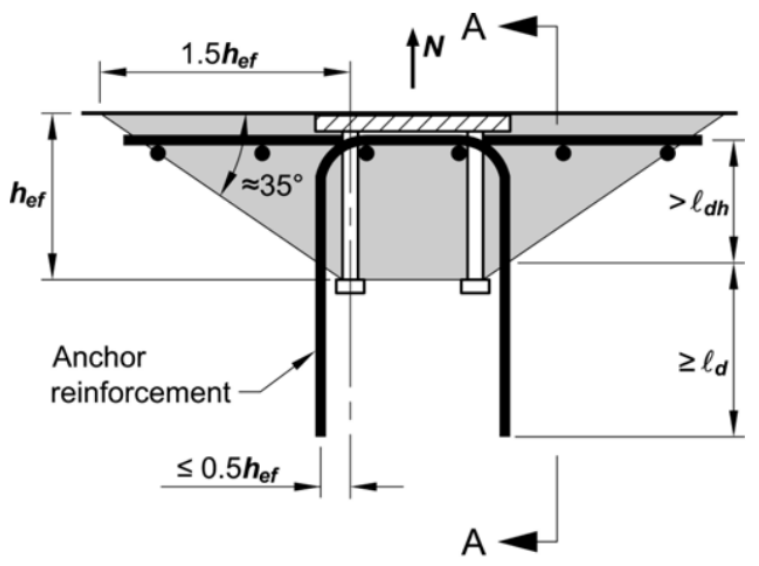

Elevation

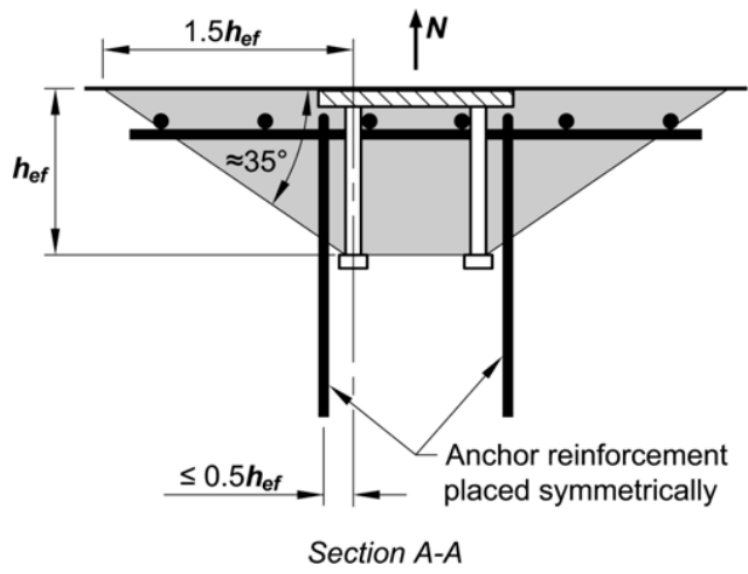

Figure 9 
Specifically, for example when calculating the design strength of the anchor the only difference is that in the Canadian Codes, an appropriate resistance factor $\Phi_{s}$ is used and also the resistance modification factor, $\mathrm{R}$, is added in accordance with Clause D.5.3. When calculating the basic concrete breakout strength and the pull-out capacity of a single anchor in tension in cracked concrete the only additions in the Canadian Codes are the $\Phi_{\mathrm{c}}$ factor for concrete compressive strength and the resistance modification factor, $\mathrm{R}$. The factors used in $\mathrm{ACl}$ Standards, for taking group effects into account in concrete breakout strength, do not change and they remain the same. However for cast-in headed studs and headed bolts with 11 in $\leq h_{\text {ef }} \leq 25$ in. The equation is given as $N_{b r}=16 \lambda_{a}\left(f_{c}^{\prime}\right)^{1 / 2}\left(h_{e f}\right)^{5 / 3}$.

The concrete side-face blowout resistance of a headed anchor in tension is also similar in the $\mathrm{ACl}$ Standards except for the exclusion of $\mathrm{R}$ and a different coefficient number in the beginning of the equation. This coefficient is different because units used in the American Standards are empirical whereas the Canadian Code is written in metric. The equation in $\mathrm{ACl}$ is given as $\mathrm{N}_{\mathrm{sbr}}=$ $160 c_{a 1} \lambda_{a}\left(A_{b r g}\right)^{1 / 2}\left(f_{c}^{\prime}{ }_{c}\right)^{1 / 2}$. The factored bond strength of adhesive anchors given in ACl Standards is very similar to the Canadian Codes. The only difference is the exclusion of the $\Phi_{c}$ factor and R. Also $\mathrm{C}_{\mathrm{Na}}$ is calculated with different numbers in the formula due to the differences in the units used in the equation.

Design requirements in shear for anchors in $\mathrm{ACl}$ standards is again similar to Canadian Codes. The maximum factored resistance of an anchor in shear, $V_{s a r}$, and concrete breakout strength of anchor in shear for both standards is exactly the same with the only differences appearing due to the differences in units used for $\mathrm{ACl}$ and $\Phi_{c}$ factor and $\mathrm{R}$. In addition, the concrete pry-out resistance of an anchor in shear in ACl Standards is exactly same as the Canadian Codes. 


\section{Conclusion}

When designing anchors, both the strength capacity of steel and concrete the anchor is embedded into must be considered. The Concrete Capacity Design method currently used in both $\mathrm{ACl}$ and Canadian Standards utilizes a $35^{\circ}$ projected failure surface for the embedded portion of the anchor. The expressions used in this method have been calibrated to the extensive database of experimental tests that have been conducted in the last 30 years. The CCD Method addresses a variety of anchor types, and design conditions, while providing a more consistent level of safety for a wider range of anchorage failure modes for both cracked and uncracked concrete.

This project discussed various different types of anchors, their design, and different failure modes that can occur under different loadings. Anchors transfer tensile and shear loads via a mechanism called mechanical interlock. The contact points in-between the anchor and concrete transfers the shear and tensile load via bearing pressure. At failure, this bearing pressure can be in excess of ten times the concrete's compressive strength. 


\section{References}

1. ACl design handbook. (1991). Detroit, Mich.: American Concrete Institute.

2. Concrete Design Handbook. (2015). 4th ed. Toronto: Cement Assoication of Canada.

3. Mohr, W. (2008). The Design Provisions of the New AWS Structural Welding Code - Titanium. Materials Science Forum, 580-582,.

4. Brzev, S. and Pao, J. (2006). Reinforced concrete design. 2nd ed. Toronto: Pearson Prentice Hall.

5. Tensile Capacity of Short Anchor Bolts and Welded Studs: A Literature Review. (1982). ACI Journal Proceedings, 79(4).

6. Structural welding code--reinforcing steel. (2011). Miami, FL: American Welding Society.

7. Pallarés, L. and Hajjar, J. (2010). Headed steel stud anchors in composite structures, Part I: Shear. Journal of Constructional Steel Research, 66(2), pp.198-212.

8. Anderson, N. and Meinheit, D. (2005). Pryout Capacity of Cast-In Headed Stud Anchors. PCI Journal, 50(2), pp.90-112. 
